\title{
Functional phage display of leech-derived tryptase inhibitor (LDTI): construction of a library and selection of thrombin inhibitors ${ }^{1}$
}

\author{
Aparecida S. Tanaka $a^{\mathrm{a}, \mathrm{b}, *}$, Melissa M. Silva ${ }^{\mathrm{a}}$, Ricardo J.S. Torquato ${ }^{\mathrm{a}}$, Maria A.E. Nogutic, \\ Claudio A.M. Sampaio ${ }^{\mathrm{a}}$, Hans Fritz ${ }^{\mathrm{b}}$, Ennes A. Auerswald ${ }^{\mathrm{b}}$ \\ ${ }^{a}$ Departamento de Bioquímica, UNIFESP-EPM, Rua 3 de Maio 100, 04044-020 São Paulo, SP, Brazil \\ ${ }^{\mathrm{b}}$ Abteilung für Klinische Chemie und Klinische Biochemie in der Chirurgischen Klinik und Poliklinik, Klinikum Innenstadt der Ludwig-Maximilians \\ Universität, Munich, Germany \\ ${ }^{\mathrm{c}}$ Departamento de Medicina, Disciplina de Hematologia, UNIFESP-EPM, São Paulo, SP, Brazil
}

Received 14 June 1999; received in revised form 10 August 1999

\begin{abstract}
The recombinant phage antibody system pCANTAB $5 \mathrm{E}$ has been used to display functionally active leech-derived tryptase inhibitor (LDTI) on the tip of the filamentous M13 phage. A limited combinatorial library of $5.2 \times 10^{4}$ mutants was created with a synthetic LDTI gene, using a degenerated oligonucleotide and the pCANTAB 5E phagemid. The mutations were restricted to the $\mathrm{P} 1-\mathrm{P} 4^{\prime}$ positions of the reactive site. Fusion phages and appropriate host strains containing the phagemids were selected after binding to thrombin and DNA sequencing. The variants LDTI-2T (K8R, I9V, S10, K11W, P12A), LDTI-5T (K8R, I9V, S10, K11S, P12L) and LDTI-10T (K8R, I9L, S10, K11D, P12I) were produced with a Saccharomyces cerevisiae expression system. The new inhibitors, LDTI$2 \mathrm{~T}$ and $-5 \mathrm{~T}$, prolong the blood clotting time, inhibit thrombin $\left(K_{\mathrm{i}}\right.$ $302 \mathrm{nM}$ and $28 \mathrm{nM})$ and trypsin $\left(K_{\mathrm{i}} 6.4 \mathrm{nM}\right.$ and $\left.2.1 \mathrm{nM}\right)$ but not factor Xa, plasma kallikrein or neutrophil elastase. The variant LDTI-10T binds to thrombin but does not inhibit it. The relevant reactive site sequences of the thrombin inhibiting variants showed a strong preference for arginine in position P1 (K8R) and for valine in P1' (I9V). The data indicate further that LDTI-5T might be a model candidate for generation of active-site directed thrombin inhibitors and that LDTI in general may be useful to generate specific inhibitors suitable for a better understanding of enzyme-inhibitor interactions.
\end{abstract}

(c) 1999 Federation of European Biochemical Societies.

Key words: Phage display system; Thrombin inhibitor; Combinatorial library; Kazal-type serine proteinase inhibitor; Filamentous phage

\section{Introduction}

The actions of thrombin are central to the hemostasis of higher organisms and human beings [1]. Thrombin exhibits both pro- and anti-coagulant effects. Its three-dimensional structure reveals an unusually deep and narrow active site

\footnotetext{
*Corresponding author. Fax: (55) (11) 572-3006.

E-mail: tanaka.bioq@epm.br

1 Enzymes: thrombin (EC 3.4.21.5); trypsin (EC 3.4.21.4); plasma kallikrein (EC 3.4.21.34); factor Xa (EC 3.4.21.6); plasmin (EC 3.4.21.7); neutrophil elastase (EC 3.4.21.37).
}

Abbreviations: LDTI, leech-derived tryptase inhibitor; pIII, minor coat protein III; ELISA, enzyme-linked immunosorbent assay; moi, multiplicity of infection; cfu, colony forming unit; PCR, polymerase chain reaction; Amp, ampicillin; Kan, kanamycin; TT, thrombin time (clotting time of human blood triggered by thrombin) cleft which is the major determinant for its restricted substrate specificity $[2,3]$. The catalytic activity of thrombin is regulated physiologically by serpins such as antithrombin III, heparin cofactor II, protease nexin I and by the general protease scavenger $\alpha_{2}$-macroglobulin [4]. In addition, heterologous proteintype thrombin inhibitors are described, such as hirudin [5], haemadin [6], rhodniin [7], bothrojaracin [8], triabin [9] and ornithodorin [10]. These specific and selective inhibitors are present in hematophagous parasites where they prevent clotting of sucked blood. The best studied thrombin inhibitor is hirudin from the medical leech Hirudo medicinalis [5]. The three-dimensional structural determination of its complex with thrombin [11] as well as other three-dimensional structures of thrombin complexes with rhodniin [12] and ornithodorin [10] revealed and confirmed a two-site interaction mechanism of these protein-type inhibitors with thrombin. This is characterized by a strong interaction between the reactive site of the inhibitor and the active site cleft of thrombin as well as by extensive electrostatic interactions of various exosites of the inhibitors and of the thrombin [13].

Leech-derived tryptase inhibitor (LDTI) is a Kazal-type serine proteinase inhibitor of tryptase, trypsin and chymotryp$\sin$. The appropriate $K_{\mathrm{i}}$ values are in the nM range [14]. The small molecule consists of 46 amino acid residues and shows high similarity to the specific thrombin inhibitor rhodniin and to the plasmin and trypsin inhibitor bdellin B-3 [15]. But thrombin and plasmin are inhibited only very weakly by LDTI, $12 \%$ and $30 \%$, at a concentration of $0.2 \mu \mathrm{M}$, respectively [14]. Recombinant LDTI (r-LDTI) is equivalent to isolated native material [16] and was used for elucidation of the three-dimensional structure in solution. r-LDTI shows a typical Kazal-type inhibitor fold as described earlier for other ovomucoid inhibitors by Bode and Huber [17] but it has a small internal deletion at the $\mathrm{N}$-terminus [18]. The crystal structure of the rLDTI-bovine trypsin complex confirmed the structure in solution [19] and proved the typical substrate-like 'canonical' interaction with trypsin as well as the inhibition model of 'small' serine proteinase inhibitors postulated by Laskowski and Kato [20].

Combinatorial mutations of peptides and proteins and their display on the tips of filamentous bacteriophages became an important tool for the production and screening of protein variants with altered binding affinities in the last decade. Several phage libraries have been created and used in different ways, for example to identify new ligands for receptors [21], to define substrates for enzymes [22], to optimize binding sites in hormones [23] or to select new, high affinity proteinase inhibitors [24-29]. The display of antigenic peptides and of antigen 
binding domains seems to be the most effective application of this technology [30-32].

We have evaluated the antibody expression and display system pCANTAB 5E with the cysteine proteinase inhibitor chicken cystatin earlier [33] and present data here on expression of the tryptase inhibitor LDTI, on the construction of a restricted combinatorial phage/phagemid library, on screening thrombin inhibitors and on inhibition kinetics. In a parallel approach, we have constructed and expressed new bivalent $r$ LDTI thrombin inhibitors by structure-based protein design. There, the reactive site loop of LDTI was trimmed by cassette mutagenesis to fit into thrombin's narrow active site cleft and the C-terminus of the inhibitor was prolonged with an acidic linker peptide which binds to the fibrinogen exosite of thrombin [34]. The results presented here open the possibility to create new monovalent thrombin reactive site inhibitors by phage display.

\section{Materials and methods}

\subsection{Materials}

The recombinant phage antibody system (pCANTAB 5E) and detection module were purchased from Pharmacia and used as described in the instruction manual. All reagents and methods were used or carried out as described by Auerswald et al. [16]

\subsection{LDTI cloning into $p C A N T A B 5 E$}

A LDTI gene was obtained by polymerase chain reaction (PCR) amplification using the LDTI cloning vector pRM 3.1.10 [16], the forward PPEAKI 5'-AAA ATT AAC TGG CCC AGC AGG CCA AGA AGG TTT GCG CAT GCC CAA AG-3' and the reverse primer: PPEAKII 5'-AAA AGG AAA ATG CGG CCG CGT TTA AAA TAC CGG TTG GAC AAG AAA C-3' from MWG-Biotech (Munich, Germany). The underlined sequences represent the recognition sites for SfiI and NotI, respectively, both were used for insertion of the PCR product into the phagemid vector pCANTAB 5E.

\subsection{Construction of LDTI mutant library}

The correct DNA sequence of the amplified LDTI gene was con- firmed using S1 and S6 primers for pCANTAB 5E. The new vector was named pAT 13.1.8 LDTI and expressed on the tips of phages or alternatively in the periplasma of Escherichia coli using standard molecular cloning methods. A degenerate oligonucleotide (LOOP4) was synthesized with several mutations. It contains the nucleotide sequence NNSDBB $(\mathrm{N}=\mathrm{A} / \mathrm{T} / \mathrm{C} / \mathrm{G} ; \mathrm{S}=\mathrm{G} / \mathrm{C} ; \mathrm{B}=\mathrm{C} / \mathrm{G} / \mathrm{T}$ and $\mathrm{D}=\mathrm{A} / \mathrm{G} /$ T) which codes for a restricted pool of amino acids at the positions P1-P4' [35] of the inhibitor. A population of complementary DNA strands was constructed using the LOOP4 oligonucleotide and the backward primer PPEAK with Taq polymerase (see Fig. 1). The resulting double stranded material was cleaved with $S p h \mathrm{I}$ and $N s i \mathrm{I}$ and ligated into dephosphorylated phagemid vector pAT 13.1.8 missing its small $S p h \mathbf{I}-N s i \mathrm{I}$ cassette. The mixture of ligation products was used to transform E. coli TG1 cells (K12(lac-pro), supE, thi, hsdD5/F', traD36, proAB, lacIq, lacZ $\Delta \mathrm{M} 15$ ) and to create the library.

\subsection{Selection of LDTI variants binding thrombin}

Transformed E. coli TG1 cells harboring the phagemids were grown at $30^{\circ} \mathrm{C}$ in $2 \times \mathrm{YT}$ medium containing $200 \mu \mathrm{g}$ ampicillin (Amp) $/ \mathrm{ml}$ and $2 \%(\mathrm{w} / \mathrm{v})$ glucose up to an optical density of $A_{550}=0.5-0.7$, helper phages $(\mathrm{M} 13 \mathrm{KO} 7)$ were added (multiplicity of infection $(\mathrm{moi})=100)$, in order to produce fusion phages and growth was continued for $1 \mathrm{~h}$ at $37^{\circ} \mathrm{C}$. The fermentation broth was centrifuged, bacteria were collected and resuspended in $2 \times \mathrm{YT}$ fresh medium $(200 \mu \mathrm{g} \mathrm{Amp} / \mathrm{ml}$ and $50 \mu \mathrm{g}$ kanamycin $(\mathrm{Kan}) / \mathrm{ml})$ and grown for $12-15 \mathrm{~h}$, at $37^{\circ} \mathrm{C}$. The broth was centrifuged, the pellet discarded and the fusion phage particles (supernatant) were used for repetitive selection by affinity binding to bovine thrombin, applying an ELISA-like assay [33]. After the second round of selection, bound fusion phages were eluted and used for transfection of $E$. coli cells. Thirty colonies were grown to amplify phage particles and finally the constructs pAT15.1.2.T, pAT15.1.5T and pAT15.1.10T were selected and used for further analyses.

\subsection{Subcloning of LDTI variant genes and expression in}

Saccharomyces cerevisiae

A secretory yeast expression system (pVT102U- $\alpha$ and $S$. cerevisiae strain S-78, kindly provided by T. Vernet, Montreal, Que., Canada) was used for production of LDTI variants. Therefore, fragments of pAT15.1.2T, $-5 \mathrm{~T}$ and $-10 \mathrm{~T}$ were amplified and modified by PCR. The forward primer used (5'-CCCAGCAGGCCTCTAGATAAAAGAAAGAAGGTTTGCGCATGCCC-3') encodes the C-terminal end of the alpha mating factor signal sequence containing the cleavage site for KEX2 protease as well as the N-terminus of the LDTI variant whereas the reverse primer used (5'-GGCCGCGAAGCTTAT-

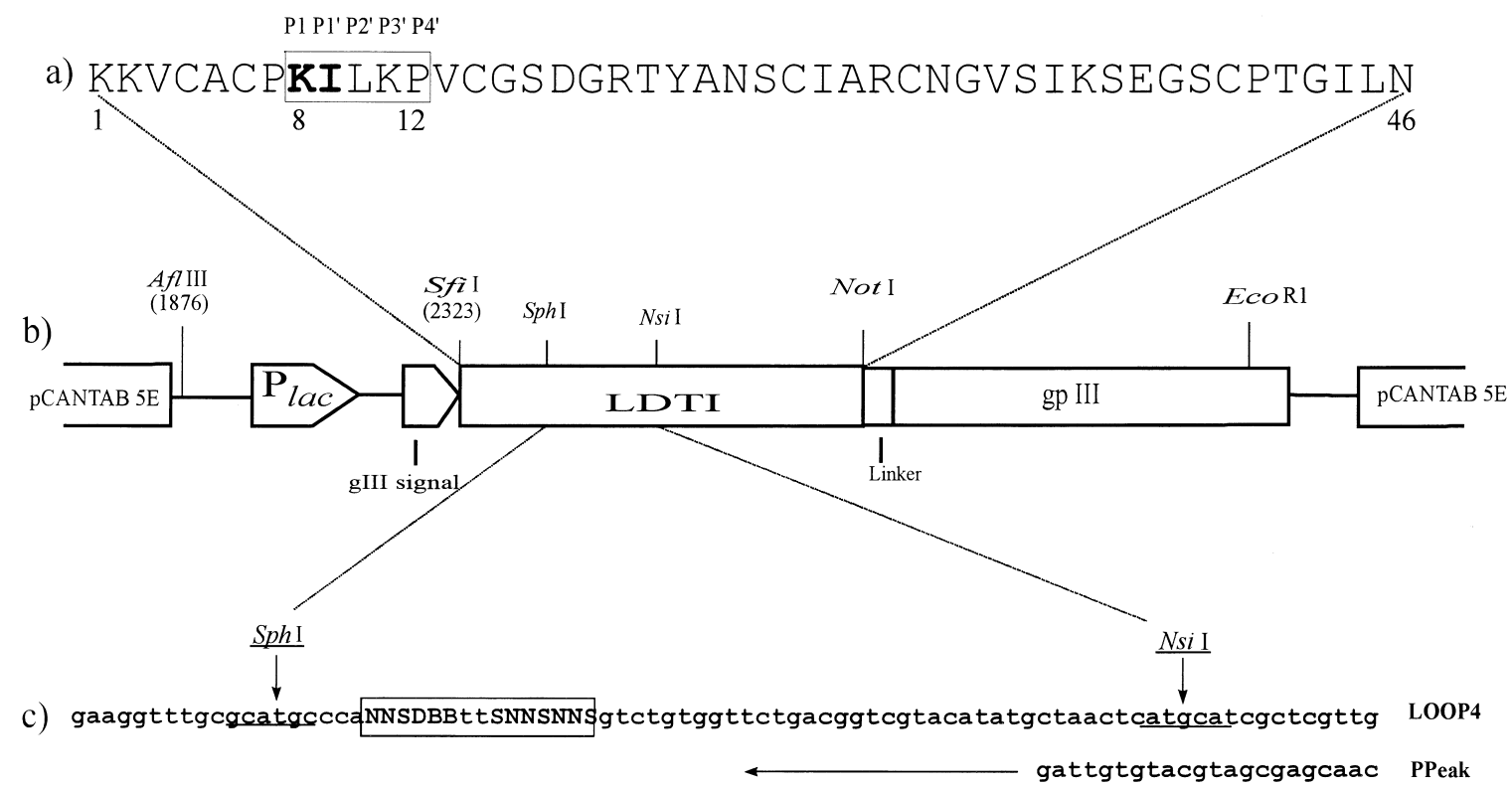

Fig. 1. Primary structure of LDTI, schematic representation of the pCANTAB 5E-LDTI construct (pAT 13.1.8.) and DNA sequences of LOOP4 and PPeak. A: Amino acid sequence of LDTI; the reactive site positions P1-P4' are boxed. B: Schematic representation of the important parts of phagemid pAT13.1.8: P lac, lactose promoter; gIII signal, signal sequence of the gene III product; gene minor coat protein III (gpIII); number in brackets, base pair positions of pCANTAB 5E; DNA sequences of the degenerated oligonucleotide LOOP4 $(\mathrm{N}=\mathrm{A} / \mathrm{T} / \mathrm{C} / \mathrm{G}$; $\mathrm{S}=\mathrm{G} / \mathrm{C} ; \mathrm{B}=\mathrm{C} / \mathrm{G} / \mathrm{T}$ and $\mathrm{D}=\mathrm{A} / \mathrm{G} / \mathrm{T} ;$ and of the the primer PPeak 
TAGTTTAAAATACCGGTTGGACAAGAACC- $3^{\prime}$ ) encodes the Cterminus of LDTI. The expression cassettes were ligated with $\mathrm{XbaI} /$ HindIII-cleaved and dephosphorylated pVT102U- $\alpha$ vectors. The three resulting yeast expression vectors were used to transform $S$. cerevisiae strains S-78 [36], separately. Standard yeast cultivation and expression experiments were carried out (pre-culture 2-3 days, $100 \mathrm{ml} \mathrm{SD(+)}$ medium; main culture 4 days with $900 \mathrm{ml}$ fresh YED-medium at $28^{\circ} \mathrm{C}$ at $220 \mathrm{rpm}$ ) with S-78 strains $\mathrm{x}$ pAT16.1.2T, pAT17.1.5T and pAT18.1.10T. During cultivation the cell density (OD 700) was determined daily, the $\mathrm{pH}$ adjusted to 6.0 with $\mathrm{NaOH}$ when necessary and $10 \mathrm{ml}$ of yeast extract stock solution $(50 \% \mathrm{w} / \mathrm{v})$ and $30 \mathrm{ml}$ of glucose $(50 \% \mathrm{w} / \mathrm{v})$ were added daily. Thrombin inhibitory activity was analyzed according to Strube et al. [6].

\subsection{Purification of LDTI variants}

Transformed yeast cells were harvested after $144 \mathrm{~h}$ cultivation $\left(6000 \times g, 20 \mathrm{~min}, 4^{\circ} \mathrm{C}\right)$. The supernatants were applied to DEAESephadex A-50 (batch form) and bound proteins were eluted with $0.05 \mathrm{M}$ Tris- $\mathrm{HCl}, \mathrm{pH} 8.0,0.5 \mathrm{M} \mathrm{NaCl}$. The trypsin inhibitory activities were measured according to Erlanger et al. [37]. The material was purified further by affinity chromatography on trypsin-Sepharose prepared according to the manufacturer's instructions (Pharmacia). The LDTI-variants were analyzed by SDS-PAGE [38] and by protein sequencing (473A, Applied Biosystems GmbH, Weiterstadt, Germany).

\subsection{Determinations of equilibrium dissociation constants ( $\left.K_{i}\right)$}

The equilibrium dissociation constants of complexes between the variants and bovine thrombin, bovine trypsin, human factor $\mathrm{Xa}$, human plasma kallikrein or human neutrophil elastase were determined using the method described by Bieth [39]. Briefly, the serine proteases were incubated with different concentrations of the variants in $0.1 \mathrm{M}$ Tris- $\mathrm{HCl}\left(\mathrm{pH} 8.0,0.1 \%\right.$ Triton $\left.\mathrm{X}-100,37^{\circ} \mathrm{C}\right)$ and the residual enzyme activities were measured after addition of chromogenic substrates: S2238 (Chromogenix), Ac.Phe-Arg-pNa (kind gift from Dr. L. Juliano, Departamento de Biofisica, UNIFESP-EPM), S2222 (Chromogenix), S2302 (Chromogenix) and MeoSuc.Ala-Ala-Pro-Val-pNa (Calbiochem) for the enzymes above, respectively. Apparent $K_{\mathrm{i}}$ values were calculated by fitting the steady-state velocities to the equation for tight-binding inhibitor using a non-linear regression analysis [40].

\subsection{Clotting time-thrombin time (TT)}

Human blood was collected from healthy volunteers $(15 \mathrm{ml})$ and transferred to a tube containing $1.5 \mathrm{ml} \mathrm{3.8 \%} \mathrm{sodium} \mathrm{citrate.} \mathrm{Eryth-}$ rocytes, platelets and leukocytes were removed by centrifugation
$(1450 \times g, 15 \mathrm{~min}$, room temperature). The plasma was transferred to a new tube and stored on ice. The TT prolongation was determined by adding different concentrations of protease inhibitors to $200 \mu \mathrm{l}$ of normal plasma and $100 \mu \mathrm{l}$ of $2.5 \mathrm{U}$ of thrombin (Sigma, St. Louis, MO, USA). The clotting times were measured and the data were compared with data from normal plasma.

\section{Results}

The synthetic LDTI gene from pRM 3.1.10 [16] was amplified and ligated into pCANTAB 5E. E. coli transformants were selected after DNA sequencing. The phagemid pAT 13.1.8. contains the correct LDTI sequence. This construct allows expression of the trypsin-binding fusion protein LDTI-protein III on the tip of the filamentous phage. The binding activities of the resulting recombinant phages were detected after $10^{3}$-fold enrichment by biopanning against immobilized trypsin. As a negative control M13 phages were used. The trypsin-binding LDTI phages react with anti M13 antibody as expected (data not shown).

The phagemid pAT 13.1.8 was used to construct a library of LDTI variants carrying mutations at the reactive site positions P1-P4'. The strategy of library construction is shown schematically in Fig. 1. The mutated double-stranded fragments were ligated into the LDTI gene and phagemids and phages were produced. The library titer was $5.2 \times 10^{4}$ colony forming unit $(\mathrm{cfu}) / 2 \mathrm{ml}$. The library was amplified to $3.5 \times 10^{9}$ $\mathrm{cfu} / \mathrm{ml}$ and used to identify thrombin-binding LDTI variants. Therefore, LDTI fusion phages were immobilized by biopanning on thrombin-coated microtiter plates. Each selection round was monitored by phage titration (dilution and plating on SOBAG plates containing Amp); the enrichment was only 10 -fold. In total, 30 colonies were isolated carrying the appropriate phagemids and used to produce fusion phages. Finally, five colonies were selected and the phagemid DNAs of them were partially sequenced. Three DNA sequences were detected (5'-CGCGTCTTGTCCCTGG-3' ; 5'-CGGGTTTTGTCCC-

Table 1

Comparison of the amino acid sequence of the reactive site region of LDTI variants selected to thrombin with the cleavage site regions of natural substrates and the reactive site of a specific inhibitor of thrombin

\begin{tabular}{|c|c|c|c|c|c|c|c|c|c|c|}
\hline & P3 & $\mathrm{P} 2$ & $\mathbf{P 1}$ & P1' & $\mathbf{P 2} \mathbf{2}^{\prime}$ & P3' & P4' & $\mathrm{P} 5^{\prime}$ & $\mathrm{P}^{\prime}$ & $K \mathbf{i}(\mathrm{nM})$ \\
\hline \multicolumn{11}{|l|}{ Substrates cleavage sites ${ }^{a}$} \\
\hline Fibrinogen A & $14 \mathrm{G}$ & $\mathrm{V}$ & $\mathbf{R}$ & G & $\mathrm{P}$ & $\mathrm{R}$ & $\mathrm{V}$ & $\mathrm{V}$ & $\mathrm{E}$ & \\
\hline Fibrinogen B & $12 \mathrm{~S}$ & A & $\mathbf{R}$ & G & $\mathrm{H}$ & $\mathrm{R}$ & $\mathrm{P}$ & $\mathrm{L}$ & $\mathrm{D}$ & \\
\hline Thrombin receptor & $39 \mathrm{D}$ & $\mathrm{P}$ & $\mathbf{R}$ & $\mathbf{S}$ & $\mathrm{F}$ & $\mathrm{L}$ & $\mathrm{L}$ & $\mathrm{R}$ & $\mathrm{N}$ & \\
\hline Protein $\mathrm{C}$ & $167 \mathrm{D}$ & $\mathrm{P}$ & $\mathbf{R}$ & $\mathbf{L}$ & $\mathrm{I}$ & $\mathrm{D}$ & G & $\mathrm{K}$ & M & \\
\hline Factor XIII & $36 \mathrm{~V}$ & $\mathrm{P}$ & $\mathbf{R}$ & G & $\mathrm{V}$ & $\mathrm{N}$ & $\mathrm{L}$ & $\mathrm{Z}$ & $\mathrm{Z}$ & \\
\hline Factor V & $707 \mathrm{G}$ & I & $\mathbf{R}$ & $\mathbf{S}$ & $\mathrm{F}$ & $\mathrm{R}$ & $\mathrm{N}$ & $\mathrm{S}$ & $\mathrm{S}$ & \\
\hline Factor VIII & $738 \mathrm{G}$ & $\mathrm{P}$ & $\mathbf{R}$ & $\mathbf{S}$ & $\mathrm{F}$ & $\mathrm{S}$ & Q & $\mathrm{N}$ & S & \\
\hline Optimal cleavage sequence ${ }^{b}$ & (F) & $\mathrm{P}$ & $\mathrm{R}$ & $\mathrm{S}$ & $\mathrm{F}$ & $\mathrm{R}$ & $?$ & & & \\
\hline Rhodniin domain $1^{\mathrm{c}}$ & $8 \mathrm{C}$ & $\mathrm{P}$ & $\mathbf{H}$ & $\mathbf{A}$ & $\mathrm{L}$ & $\mathrm{H}$ & $\mathrm{R}$ & $\mathrm{V}$ & $\mathrm{C}$ & $3.8^{\mathrm{d}}$ \\
\hline LDTI wild-type & $6 \mathrm{C}$ & $\mathrm{P}$ & $\mathbf{K}$ & $\mathbf{I}$ & $\mathrm{L}$ & $\mathrm{K}$ & $\mathrm{P}$ & $\mathrm{V}$ & $\mathrm{C}$ & $>300$ \\
\hline LDTI $2 \mathrm{~T}$ & $6 \mathrm{C}$ & $\mathrm{P}$ & $\mathbf{R}$ & $\mathbf{V}$ & $\mathrm{L}$ & $\mathrm{W}$ & A & $\mathrm{V}$ & $\mathrm{C}$ & 302.0 \\
\hline LDTI 5T (3 times) & $6 \mathrm{C}$ & $P$ & $\mathbf{R}$ & $\mathbf{V}$ & $\mathrm{L}$ & $\mathrm{S}$ & $\mathrm{L}$ & V & $\mathrm{C}$ & 28.0 \\
\hline LDTI $10 \mathrm{~T}$ & $6 \mathrm{C}$ & $\mathrm{P}$ & $\mathbf{R}$ & $\mathbf{L}$ & $\mathrm{L}$ & $\mathrm{D}$ & $\mathrm{I}$ & $\mathrm{V}$ & $\mathrm{C}$ & n.i. \\
\hline
\end{tabular}

n.i.: not inhibited.

${ }^{a}$ Cleavage sites of thrombin substrates [42]. Rhodniin domain 1 sequence [7].

${ }^{\mathrm{b}}$ Optimal cleavage sequence for thrombin [19].

${ }^{\mathrm{c}}$ Rhodniin domain 1 sequence [7].

${ }^{\mathrm{d}}$ M. Otte (unpublished data). 
TC-3'; 5'-AGGGTCTTGTCGTTG-3') encoding RVLSL (LDTI-5T); the DNA sequence (5'-CGCGTCTTGTGGGCC-3') encoding RVLWA (LDTI-2T) and (5'-CGGTTGTTGGACATC-3') for RLLDI (LDTI-10T) were found only once (Table 1). All constructs showed the amino acid codons (CGC; CGG; AGG) for arginine at position 8 in P1. It is well known that thrombin substrates are cleaved preferentially after an arginine which binds to the S1 subsite (Table 1).

In order to characterize the inhibition profile of the LDTI variants it was necessary to produce more material, but it was difficult to generate enough fusion phages with the system used. An alternative periplasmic expression approach in $E$. coli was also not successful, although the suppliers of the pCANTAB 5E system are favoring this route. Therefore, DNA fragments containing LDTI-2T, $-5 \mathrm{~T}$ and $-10 \mathrm{~T}$ were subcloned, expressed and secreted with the pVT102U- $\alpha S$. cerevisiae system. The expression levels of these variants were between 15 and $45 \mathrm{mg} / \mathrm{l}$ as calculated by trypsin inhibition assays and titrated trypsin as standard enzyme. It was shown before that LDTI [14,19] binds and inhibits trypsin in an equimolar ratio. LDTI-2T, $-5 \mathrm{~T}$ and $-10 \mathrm{~T}$ were isolated from the yeast supernatant, purified by ion-exchange (DEAE-Sephadex) and affinity chromatography (trypsinSepharose). The purified material of all three variants showed only one band after SDS-PAGE (data not shown). The molecular masses of the LDTI variants were around $5000 \mathrm{Da}$, which is close to the theoretical value for LDTI wild-type (4737.6 Da). The expected N-terminal amino acids of the three variants including the mutated positions P1-P4' were confirmed by amino acid sequencing $(14,23$ and 23 amino acid residues for variants $2 \mathrm{~T}, 5 \mathrm{~T}$ and $10 \mathrm{~T}$, respectively). The inhibition of human factor Xa, human plasma kallikrein and human neutrophil elastase by the three variants were tested up to a concentration of $0.5 \mu \mathrm{M}$ of the inhibitors, but the three serine proteinases are not inhibited at these conditions. Finally, the equilibrium dissociation constants $\left(K_{\mathrm{i}}\right)$ of complexes between the LDTI variants and bovine trypsin or bovine thrombin were determined (Table 2). The variants LDTI-2T and LDTI-5T are strong trypsin and thrombin inhibitors with $K_{\mathrm{i}}$ values of $6.4 \mathrm{nM}$ and $2.1 \mathrm{nM}$ for trypsin and $302 \mathrm{nM}$ and $28 \mathrm{nM}$ for thrombin, respectively. Both variants increase the clotting time of human blood triggered by thrombin (TT) in a concentration-dependent manner. The prolongation of TT by LDTI-2T and LDTI-5T is 1.8 - and 2.0-fold at $0.5 \mu \mathrm{M}$, respectively. The LDTI wild-type and LDTI-10T have no effect on blood clotting (Fig. 2). The LDTI-10T is the weakest inhibitor of the three variants, its $K_{\mathrm{i}}$ with trypsin is $12 \mathrm{nM}$. A $K_{\mathrm{i}}$ value with thrombin could not be determined under the conditions used, although the appropriate phages bind to thrombin.

Table 2

Apparent equilibrium dissociation constants $\left(K_{\mathrm{i}}\right)$ for LDTI and its variants with selected serine proteases. $K_{\mathrm{i}}$ values $(\mathrm{nM})$

\begin{tabular}{lllll}
\hline Enzyme & LDTI & $2 \mathrm{~T}$ & $5 \mathrm{~T}$ & $10 \mathrm{~T}$ \\
\hline Bovine trypsin & 0.9 & 6.4 & 2.1 & 12 \\
Bovine thrombin & $>300^{\mathrm{a}}$ & 302 & 28 & n.i. \\
Human factor Xa & n.i. & n.i. & n.i. & n.i. \\
Human plasma kallikrein & n.i. & n.i. & n.i. & n.i. \\
Human neutrophil elastase & n.i. & n.i. & n.i. & n.i.
\end{tabular}

n.i.: not inhibited.

${ }^{a}$ Data from Morenweiser et al. [34].

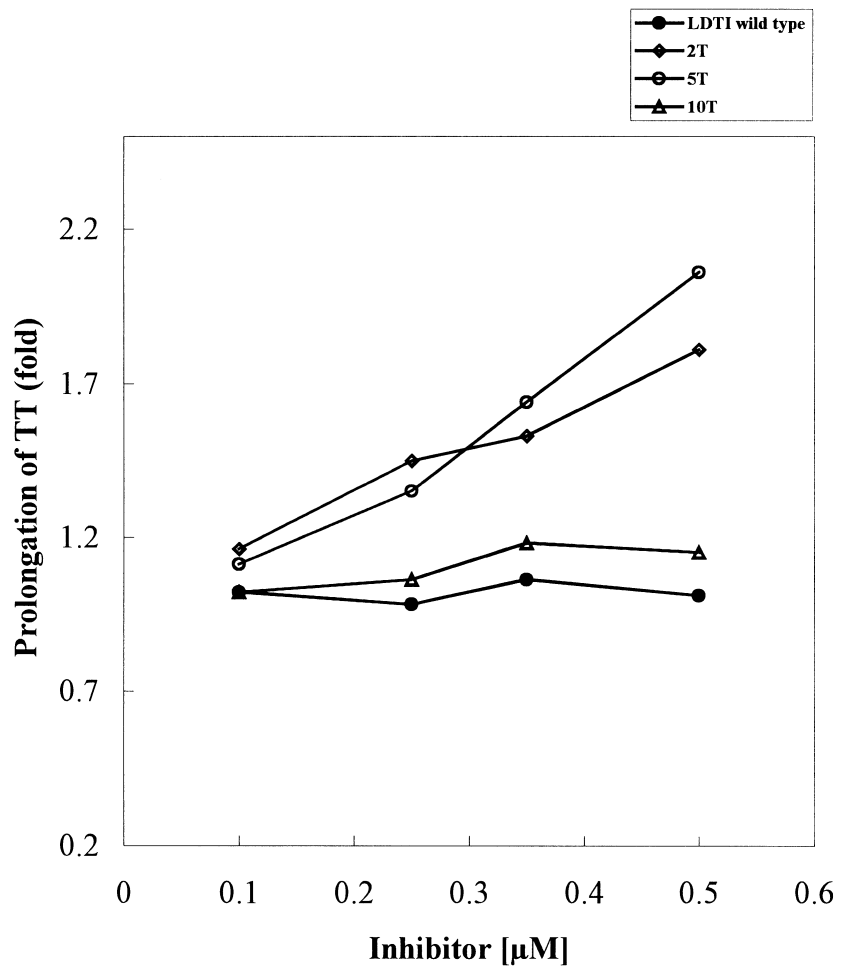

Fig. 2. Prolongation of blood clotting time-TT in normal human plasma. The inhibitor concentrations are plotted versus the prolongation factor of TT upon initiation by thrombin $(0.5 \mathrm{U})$. The inhibition assay was performed by addition of inhibitors to the plasma before the enzyme. The clotting time to normal plasma is $16.5 \mathrm{~s}$.

\section{Discussion}

It is well known that several protein-type thrombin inhibitors interact not only with the active site of thrombin but also with its various exosites such as the fibrinogen exosite, the heparin binding site or the antithrombin III binding site. This makes thrombin an enzyme whose interaction with inhibitors (and also with substrates) may be improved by mutations at several sites. Our aim was to evaluate a combinatorial mutation approach with LDTI and to optimize only a single, monovalent contact region which binds to the active site of thrombin thus causing inhibition. This approach was supported by: (a) structural inspection of LDTI and other thrombin inhibitors, (b) the successful phage display of another proteinase inhibitor [33] and (c) the generation of combinatory libraries of proteinase inhibitors reported in the literature. Markland and coworkers [41] e.g. described the successful creation of inhibitor variants for plasmin and plasma kallikrein using the first Kunitz domain of the human lipoprotein associated coagulation inhibitor (LACI-DI), although a comparable approach to mutate a small Kunitz-type inhibitor BPTI into a thrombin inhibitor failed [41].

Our experiments show that the Kazal-type serine proteinase inhibitor LDTI can be presented in a functionally active form on phage surfaces. This result confirms experiments with other inhibitors performed earlier such as aprotinin (BPTI) [24], plasminogen activator inhibitor (PAI-1) [25], tissue factor inhibitor (Kunitz-domain) [26] and hirudin [29]. Furthermore, it demonstrates that a very small protein (46 amino acids long) can be produced in a stable and active form.

The pCANTAB 5E system allowed the production and se- 
lection of mutated phagemids and fusion phages. The positive bindings were detected by ELISA techniques although the expression of the LDTI variants was low. Up to 30 LDTI variants were identified and five phagemids were selected. The sequences of all mutants showed at position $\mathrm{P} 1$ the codon for arginine. This arginine residue is most typical in thrombin substrates and thrombin inhibitors and is important for binding to the complementary $\mathrm{S} 1$ subsite $[2,3,42]$. The pCANTAB $5 \mathrm{E}$ system failed to produce sufficient amounts of fusion phages or of periplasmic LDTI variants for detailed inhibition studies. Therefore, the LDTI variants were subcloned, expressed and purified using the pVT102U/ $\alpha$-Saccharomyces cerevisiae system. The variant LDTI-10T binds to thrombin, but does not inhibit it. We do not know if this variant is cleaved or if it would inhibit at higher concentrations. An explanation for its weak binding could be the isoleucine residue at position $\mathrm{P}^{\prime}$, the bulky side chain of which may cause steric hindrance and obstruction during access to the active site of thrombin as suggested by van de Locht et al. [12] earlier. A comparably poor interaction is found with the Denver antithrombin III mutant, carrying leucine in P1' instead of serine [43]. Other site-directed mutagenesis experiments showed corresponding results with appropriate amino acid substitutions in the $\mathrm{P}^{\prime}$ ' position [44].

The variants LDTI-2T and $-5 \mathrm{~T}$ inhibit thrombin activity with $K_{\mathrm{i}}$ values in the nM range and prolong the clotting TT remarkably. Both variants contain the smaller valine residue at $\mathrm{P}^{\prime}$, which contributes positively to binding to the small S1' pocket at the thrombin active site cleft created by the so called '60 loop' [12]. The small difference determined in affinity to thrombin between LDTI-5T and LDTI-2T can be explained by serine in P3' (LDTI-5T) which is more favorable than the tryptophan residue in $-2 \mathrm{~T}$. The sequence $\mathrm{RVL}\left(\mathrm{P} 1-\mathrm{P} 2^{\prime}\right)$, present in both variants, is found also in a native thrombin inhibitor from the hematophagous insect Triatoma infestans (Tanaka, unpublished results).

In principle, the variants $2 \mathrm{~T}$ and $5 \mathrm{~T}$ showed 1000-10000fold weaker inhibitory activity against thrombin when compared to hirudin or rhodniin [7]. However, we have to keep in mind that the LDTI-variants are monovalent inhibitors binding only to the active site of thrombin and not to an additional exosite. The single domain 1 of rhodniin, which is probably the best monovalent inhibitor to compare with, inhibits thrombin only 8-fold stronger than LDTI-5T (M. Otte, personal communication)[45].

In conclusion, our results have increased the application range of the phage display system to a greater array of potent macromolecular inhibitors. The findings indicate that LDTI is a useful tool in generating new protease inhibitors and may cause a better understanding of enzyme-inhibitor interactions. The LDTI-5t variant could be used as a lead molecule for construction of monovalent thrombin inhibitors.

Acknowledgements: We thank Prof. T. Vernet (Biotechnology Research Institute, Montreal, Que., Canada), Prof. Cheng-Wu Chi, Prof. Zhang You-shaing and Prof. Hu Hong-ming (Shangai Institute of Biochemistry, China) for providing the expression vector $\mathrm{pVT} 102 \mathrm{U} / \mathrm{a}$ and $S$. cerevisiae S 78, R. Mentele for the N-terminal amino acid sequencing. This work was supported by: FAPESPProc.95/9256-8 and CNPq (Brazil), SFB 469 A-3 Sonderforschungsbereich der Ludwig-Maximilians-Universität, München, the Volkswagenstiftung 71045 and the Bundesministerium für Bildung, Wissenschaft, Forschung und Technologie BMBFT 0310931 (Germany).
A.S.T. was supported by Conselho Nacional de Desenvolvimento Científico Tecnológico (CNPq).

\section{References}

[1] Davie, E.W., Fujikawa, K. and Kisiel, W. (1991) Biochemistry 30, 10364-10370.

[2] Bode, W., Mayr, I., Baumann, U., Huber, R., Stone, S.R. and Hofsteenge, J. (1989) EMBO J. 8, 3467-3475.

[3] Bode, W., Turk, D. and Karshikov, A. (1992) Protein Sci. 1, 426-471.

[4] Olson, S.T. and Björk, I. (1992) in: Thrombin Structure and Function (Berliner, L.J., Ed.), pp. 159-217, Plenum Press, New York.

[5] Walsmann, P. and Markwardt, F. (1981) Pharmazie 36, 653-660.

[6] Strube, K-H., Kröger, B., Bialojan, S., Otte, M. and Dodt, J. (1993) J. Biol. Chem. 268, 8590-8595.

[7] Friedrich, T., Kröger, B., Bialojan, S., Lemaire, H.G., Höffken, H.W., Reuschenbach, P., Otte, M. and Dodt, J. (1993) J. Biol. Chem. 268, 16216-16222.

[8] Zingali, R.B., Jandrot-Perrus, M., Guillin, M-C. and Bon, C. (1993) Biochemistry 32, 10794-10802.

[9] Noeske-Jungblut, C., Haendler, B., Donner, P., Alagon, A., Possani, L. and Schleuning, W-D. (1995) J. Biol. Chem. 270, 2862928634

[10] Van de Locht, A., Stubbs, M., Bode, W., Friedrich, T., Bolllschweiler, C., Höffken, W. and Huber, R. (1996) EMBO J. 15, 6011-6017.

[11] Rydel, T.J., Ravichandran, K.G., Tulinsky, A., Bode, W., Huber, R., Roitsch, C. and Fenton, J.W. (1990) Science 249, 277-280.

[12] Van de Locht, A., Lamba, D., Bauer, M., Huber, R., Friedrich, T., Kröger, B., Höffken, W. and Bode, W. (1995) EMBO J. 14, 5149-5157.

[13] Stubbs, M.T. and Bode, W. (1995) Trends Biochem. Sci. 20, 23 28.

[14] Sommerhoff, C.P., Söllner, C., Mentele, R., Piechottka, G.P., Auerswald, E.A. and Fritz, H. (1994) Biol. Chem. Hoppe-Seyler 375, 685-694

[15] Fink, E., Rehm, H., Gippner, C., Bode, W., Eulitz, M., Machleidt, W. and Fritz, H. (1986) Biol. Chem. Hoppe-Seyler 367, $1235-1242$

[16] Auerswald, E.A., Morenweiser, R., Sommerhoff, C.P., Piechottka, G.P., Eckerskorn, C., Gürtler, L.G. and Fritz, H. (1994) Biol. Chem. Hoppe-Seyler 375, 695-703.

[17] Bode, W. and Huber, R. (1992) Eur. J. Biochem. 204, 433-451.

[18] Mühlhahn, P., Czisch, M., Morenweiser, R., Habermann, B., Engh, R.A., Sommerhoff, C.P., Auerswald, E.A. and Holak, T.A. (1994) FEBS Lett. 355, 290-296.

[19] Stubbs, M.T., Morenweiser, R., Stürzebecher, J., Bauer, M., Bode, W., Huber, R., Piechottka, G.P., Matschiner, G., Sommerhoff, C.P., Fritz, H. and Auerswald, E.A. (1997) J. Biol. Chem. 272, 19931-19937.

[20] Laskowski, Jr.M. and Kato, I. (1980) Annu. Rev. Biochem. 49, 593-626.

[21] O'Neil, K.T., Hoess, R.H., Jackson, S.A., Ramachandran, N.S., Mousa, S.A. and Degrado, W.F. (1992) Proteins 14, 509-515.

[22] Matthews, J.D. and Wells, J.A. (1993) Science 260, 1113-1117.

[23] Lowman, H.B. and Wells, J.A. (1993) J. Mol. Biol. 234, 564-578.

[24] Roberts, B.L., Markland, W., Ley, A.C., Kent, R.B., White, D.W., Guterman, S.K. and Ladner, R.C. (1992) Proc. Natl. Acad. Sci. USA 89, 2429-2433.

[25] Pannekoek, H., van Meijer, M., Schleef, R.R., Loskutoff, D.J. and Barbas III, C.R. (1993) Gene 128, 135-140.

[26] Dennis, M.S. and Lazarus, R.A. (1994) J. Biol. Chem. 269, 22129-22136

[27] Wang, C-I., Yang, Q. and Craik, C.S. (1995) J. Biol. Chem. 270, $12250-12256$

[28] Röttgen, P. and Collins, J. (1995) Gene 164, 243-250.

[29] Wirsching, F., Opitz, T., Dietrich, R. and Schwienhorst, A. (1997) Gene 204, 177-184.

[30] Barbas III, C.F., Kang, A.S., Lerner, R.A. and Benkovic, S.J. (1991) Proc. Natl. Acad. Sci. USA 88, 7978-7982.

[31] Marks, J.D., Hoogenboom, H.R., Bonnert, T.P., McCafferty, J., Griffiths, A.D. and Winter, G. (1991) J. Mol. Biol. 222, 581-597.

[32] Hoogenboom, H.R., de Bruïne, A.P., Hufton, S.E., Hoet, R.M., 
Arends, J.W. and Roovers, R.C. (1998) Immunotechnology 4, 120.

[33] Tanaka, A.S., Sampaio, C.A.M., Fritz, H. and Auerswald, E.A (1995) Biochem. Biophys. Res. Commun. 214, 389-395.

[34] Morenweiser, R., Auerswald, E.A., Van de Locht, A., Fritz, H., Stürzebecher, J. and Stubbs, M.T. (1997) J. Biol. Chem. 272, 19938-19942.

[35] Schechter, I. and Berger, A. (1967) Biochem. Biophys. Res. Commun. 27, 157-162.

[36] Becker, D.M. and Guartante, L. (1991) Methods Enzymol. 194, 182-187.

[37] Erlanger, B.F., Kokowsky, N. and Cohen, E. (1961) Arch. Biochem. Biophys. 95, 271-278.

[38] Laemmli, U.K. (1970) Nature 227, 680-685.
[39] Bieth, J.G. (1980) Bull. Eur. Physiopathol. Respir. 16, 183195.

[40] Morrison, J.F. (1969) Biochim. Biophys. Acta. 185, 269-286.

[41] Markland, W., Ley, A.C. and Ladner, R.C. (1996) Biochemistry $35,8045-8067$.

[42] Stubbs, M.T. and Bode, W. (1993) Thromb. Res. 69, 1-58.

[43] Stephens, A.W., Thalley, B.S. and Hirs, C.H.W. (1987) J. Biol. Chem. 262, 1044-1048.

[44] Theunissen, H.J.M., Dijkema, R., Grootenhuis, P.D.J., Swinkels, J.C., Poorter, T.L., Carati, P. and Visser, A. (1993) J. Biol. Chem. 268, 9035-9040.

[45] Otte, M. (1997) Untersuchung der Thrombin-Rhodniin Wechselwirkung mit Hilfe gentechnologisch hergestellter Rhodniinvarianten, Thesis, Technische Hochschule, Darmstadt. 